Volume 1

Issue 3 - Cardio-Oncology

Article 4

8-13-2014

\title{
An Uncommon Presentation for Cardiac Melanoma
}

\author{
Burcu Gul \\ Michael N. Young \\ David A. Slosky \\ Mark A. Lawson \\ Jeffrey N. Rottman
}

Follow this and additional works at: https://aah.org/jpcrr

Part of the Cardiovascular Diseases Commons, and the Neoplasms Commons

\section{Recommended Citation}

Gul B, Young MN, Slosky DA, Lawson MA, Rottman JN. An uncommon presentation for cardiac melanoma. J Patient Cent Res Rev. 2014;1:128-132. doi: 10.17294/2330-0698.1026

Published quarterly by Midwest-based health system Advocate Aurora Health and indexed in PubMed Central, the Journal of Patient-Centered Research and Reviews (JPCRR) is an open access, peer-reviewed medical journal focused on disseminating scholarly works devoted to improving patient-centered care practices, health outcomes, and the patient experience. 
Burcu Gul, MD, ${ }^{1}$ Michael N. Young, MD, ${ }^{1}$ David A. Slosky, MD, ${ }^{1}$ Mark A. Lawson, MD, ${ }^{1}$ Jeffrey N. Rottman, MD ${ }^{1,2}$

${ }^{1}$ Division of Cardiovascular Medicine, Department of Internal Medicine, Vanderbilt University Medical Center, Nashville, TN ${ }^{2}$ Nashville Veterans Affairs Medical Center, Nashville, TN

\section{Abstract}

A 66-year-old man with locally advanced malignant melanoma, which was surgically resected, presented with a 3-week history of dizziness, recurrent near-syncopal episodes and generalized weakness. He was found to have sustained polymorphic ventricular tachycardia in the setting of cardiac melanoma. We draw attention to an unusual presentation of malignant melanoma with cardiac metastasis and discuss both its etiology and treatment options. (J Patient-Centered Res Rev. 2014;1:128-132.)

\section{Keywords}

arrhythmias, polymorphic ventricular tachycardia, cardiac metastasis, malignant melanoma, pathology, therapy

\section{Introduction}

Primary cardiac neoplasms are rare, occurring at a frequency of $0.0017-0.33 \%{ }^{1}$ Cardiac metastases are 30 - to 40 -fold more common than primary cardiac tumors. ${ }^{2,3}$ Perhaps due to a propensity for hematogenous spread, malignant melanoma has one of the highest cardiac metastatic rates (27\%), followed by lung cancer $(21 \%)$, breast cancer $(15.5 \%)$ and lymphomas $(9.4 \%))^{3-5}$ The majority of cardiac tumors are silent and found incidentally, either on imaging or during autopsy. ${ }^{6}$ Only $10 \%$ of patients with cardiac metastases develop symptoms. ${ }^{7}$ Clinical features vary depending on tumor location and burden. Commonly reported symptoms include irritability, shortness of breath, anorexia, fatigue and palpitations. ${ }^{8}$ In cases where invasion of the myocardium is present, supraventricular and ventricular arrhythmias also may be observed..$^{9,10}$ Monomorphic ventricular tachycardia is one of the most frequently reported types of cardiac metastasis-related ventricular arrhythmia in both children and adults. ${ }^{11-14}$ In contrast, polymorphic ventricular tachycardia (PMVT) in the setting of cardiac metastasis has been reported only once. ${ }^{15}$ We describe an adult patient

Correspondence: Burcu Gul, MD, Vanderbilt University Medical Center, 2220 Pierce Avenue, 383 PRB, Nashville, TN, 37232-6300, Phone: 615-322-2318, Fax: 615-936-1872,

Email: burcu.gul@vanderbilt.edu who presented with sustained PMVT as a manifestation of metastatic melanoma, and review the manifestations and consequences of cardiac involvement of melanoma.

\section{Illustrative Case}

A 66-year-old man with a history of malignant melanoma presented with a 3-week history of dizziness, near-syncopal episodes and generalized weakness. One year earlier, he underwent wide excision and lymph node dissection for locally advanced melanoma (nodular subtype, T4N3M0, stage III) of the left heel, but did not receive adjuvant chemotherapy. He did not have a history of structural heart disease or cardiac arrhythmia.

Upon arrival, telemetry demonstrated PMVT (Figure 1), a classification based on highly variable R-R intervals and moderately variable QRS complexes. Sustained ventricular tachycardia was terminated with defibrillation, and nonsustained salvos suppressed with infusion of amiodarone and lidocaine. Antiarrhythmic therapy was transitioned to oral mexiletine and amiodarone. Subsequently, normal sinus rhythm was maintained.

Initial laboratory work-up and coronary angiography yielded normal results. Transthoracic echocardiogram (Figure 2) revealed a poorly circumscribed mass within the left ventricular apex extending to the pericardial space, thought to be consistent with a cardiac metastasis. This was subsequently confirmed by cardiac magnetic resonance imaging (Figure 3; Online Video 1 at www.aurora.org/jpcrr). Overall left ventricular systolic function was preserved.

Whole-body positron emission tomography (PET) scan showed moderate fluorodeoxyglucose uptake in the left heel with additional intensive uptake in the liver, heart, lung, peritoneum, right lower extremity soft tissue, skeleton and left cerebellum. The results were considered to be consistent with disseminated malignancy; a tissue diagnosis was declined. 


\section{Discussion}

Cardiac neoplasms are predominantly asymptomatic., ${ }^{6,16}$ Therefore, the true prevalence of cardiac tumors is unknown. Although primary cardiac tumors are rare, ${ }^{1}$ secondary or metastatic tumors are not. The estimated incidence of cardiac metastases varies widely, with estimates between $2.3 \%$ and $18.3 \%$ based on postmortem studies involving patients with metastatic disease. ${ }^{5,16,17}$ Malignant melanoma frequently metastasizes to the heart. ${ }^{18}$ This may in part reflect a special tropism of the neural crest cells to the heart; cardiac formation involves a critical neural crest invasion, certainly contributing to the endocardial cushion structures and possibly to other components of the myocardium and epicardium. ${ }^{19,20}$ The invasion of the myocardium by the tumor may result in supraventricular and ventricular arrhythmias, primarily monomorphic ventricular tachycardia. Our illustrative case represents an unusual manifestation of cardiac metastasis presenting as PMVT.

PMVT is most commonly observed in patients with structural heart disease, channelopathies, or as a consequence of drug interactions or electrolyte abnormalities. ${ }^{21-23}$ Reports of an intramural cardiac tumor leading to an unstable polymorphic rhythm are extremely rare. Whereas monomorphic ventricular tachycardia develops due to a focal reentry mechanism, ${ }^{24}$ the mechanism underlying PMVT in this context is not wellunderstood.

There are several models proposed to potentially explain this mechanism. One is based on reentry mechanism. ${ }^{24-27}$ Data obtained from human and animal studies demonstrate that after myocardial infarction, asynchronous activation of muscle fibers follows the propagation of a slow activation wavefront through the scar area. ${ }^{28}$ This area of slow conduction is the substrate for the reentry mechanism. Circuits may have multiple exit sites ${ }^{29}$ or harbor colliding wavefronts. ${ }^{26}$ Stevenson et al. ${ }^{29}$ proposed that a reentry mechanism with multiple exits maintains the PMVT in patients late after myocardial infarction. Using computer simulations of figureof-eight circuits, ${ }^{30}$ the effects of premature stimuli were simulated at elected sites in the circuit. This model helped to illustrate the exits of these one-direction pathways within the circuit (inner loop, common pathway and outer loop) as well as the differing R-R intervals and QRS morphologies corresponding to the different exits.

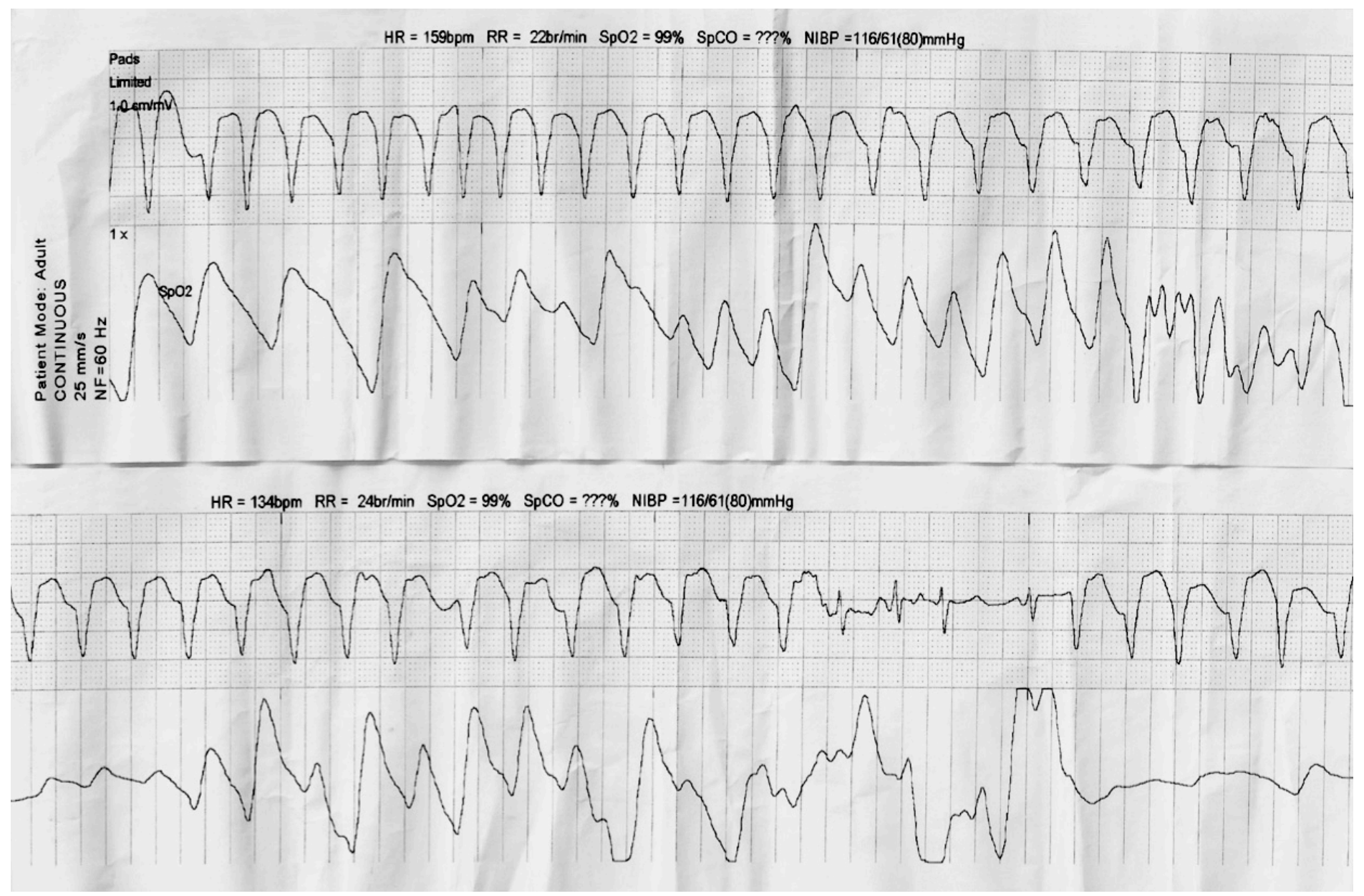

Figure 1. Cardiac monitor tracing shows polymorphic ventricular tachycardia with an average rate of 158 beats per minute. 

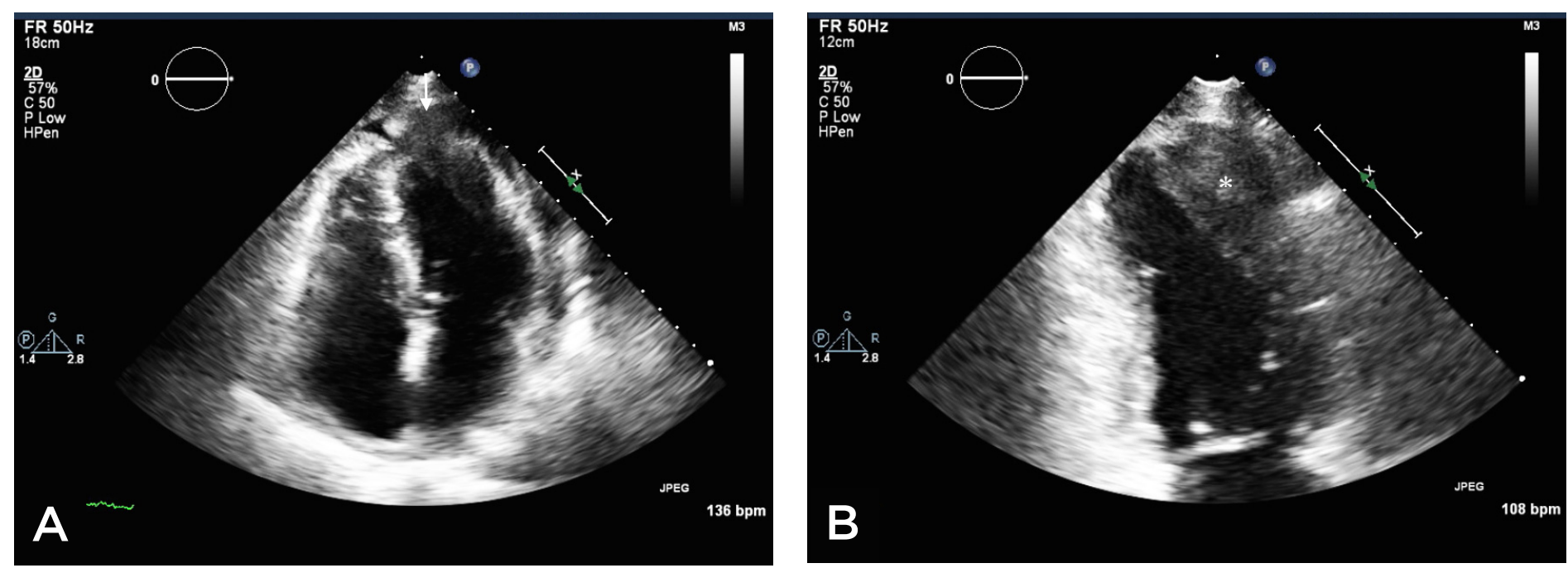

Figure 2. Transthoracic echocardiogram shows a poorly circumscribed mass within the left ventricular myocardium at the apex extending into the pericardial space with a small effusion. This is demonstrated both in the four-chamber view (A, arrow) and zoomedin two-chamber view (B, asterisk).

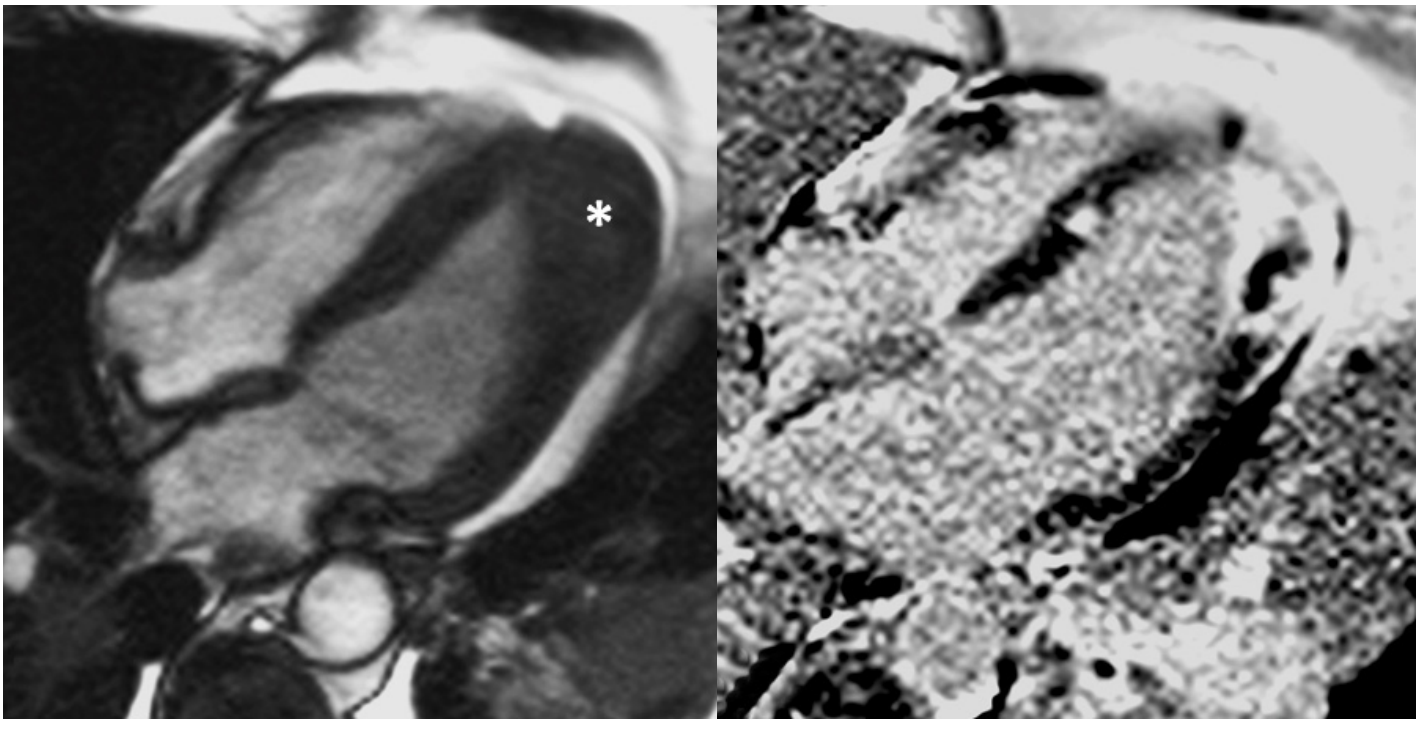

Figure 3. Cardiac magnetic resonance images delineate a $42 \times 30 \times 28-m m$ infiltrative mass (asterisk) with extensive gadolinium enhancement involving the apex.
On the other hand, Costeas et al. ${ }^{26}$ observed the rotation of the reentry wavefront in the opposite direction around the same functional block in their study with a canine model of myocardial infarction. Similar to the postinfarction model, the interdigitating melanoma and myocytes presumably played the role of patchy fibrosis intermixed with viable myocardium in our patient.

Another concept describes a spiral wave drift model. ${ }^{31,32}$ With the use of optical mapping techniques in a twodimensional excitable medium, Pertsov et al. ${ }^{32}$ illustrated drifting spiral wave activity in isolated epicardial muscle. This theory predicts that every excitable medium has a small, unexcited area that demonstrates the stable core of the spiral. Spiral waves around this core were initiated by twopoint stimulation at the same site. Drifting of the core during the excitation period resulted in changes to the ventricular tachycardia cycle length that ultimately manifested as PMVT. Attributing this manifestation of PMVT to a cardiac mass seems unlikely within this model.

The management of ventricular tachycardia depends on the diagnostic features of the arrhythmia and includes correction of electrolytes, discontinuation of the proarrhythmic drug, revascularization, defibrillation, antiarrhythmic therapy, implantable cardiac devices, ablation and resection of the arrhythmogenic focus. ${ }^{33}$ The first-line therapy remains timely termination of sustained arrhythmias and, ultimately, 
pharmacologic suppression of arrhythmia salvos. However, there is no specific recommendation for the management of PMVT in the setting of intracardiac mass.

The prognosis for patients with metastatic melanoma is poor. Treatment is generally palliative $e^{34,35}$ and not standardized. In select patients with solitary intracardiac melanoma, surgical resection may provide relief of symptoms. ${ }^{36,37}$ Resection of left-sided malignant cardiac tumors is considered to be particularly challenging due to incomplete resection. ${ }^{38}$ For complex cardiac tumors, cardiac autotransplantation (e.g. cardiac explantation, ex vivo tumor resection, reconstruction and reimplantation) also has been described..$^{39,40}$

Our patient had stage IV metastatic melanoma that was deemed unresectable. Systemic treatment is the mainstay for disseminated malignant melanoma, while radiation and surgery play an adjunctive role. Until 2010, systemic chemotherapy with dacarbazapine had an overall survival of 6 months and was the optimal therapy for widespread malignant melanoma. ${ }^{41,42}$ Over the past decade, randomized trials with two new agents have demonstrated improvement in survival: ipilimumab, a monoclonal antibody against cytotoxic T-lymphocyte antigen-4 (CTLA-4) with survival of 10 months, ${ }^{43}$ and vemurafenib, a BRAF kinase inhibitor with survival of 15 months in patients without wild-type BRAF. ${ }^{44}$ A novel concept under investigation is vaccination strategies to induce active immunity targeting cancer cells of metastatic melanoma. These strategies have included vaccination with peptides (e.g. gp100), dendritic cells, nucleic acids (e.g. Allovectin-7) and heat shock protein complexes (e.g. vitespen).$^{45}$ The applicability of these therapies to the treatment of cardiac metastases is unknown.

Complete surgical resection of cardiac metastasis with adjuvant chemotherapy appeared to improve prognosis in a small subset of patients with no disseminated disease. ${ }^{4,46}$ Hiniker et al. $^{47}$ hypothesized that radiationinduced apoptosis may stimulate an antitumor immune response ${ }^{48}$ in the setting of anti-CTLA-4 treatment. They employed radiotherapy combined with immunotherapy as a noninvasive in vivo tumor vaccine strategy in a patient with metastatic melanoma involving the liver. Follow-up PET scan demonstrated that all metastases, including nonirradiated liver lesions and a nonirradiated axillary lesion, had completely resolved.

Several important points should be emphasized in this review. Therapy for patients with malignant melanoma has improved recently. As a result, more patients may present with late complications of advanced disease, including cardiac metastasis. ${ }^{4}$ Cardiac metastasis can manifest as either monomorphic or polymorphic ventricular tachycardia. Lysis of a transmural cardiac metastasis also could result in pericardial bleeding and hemodynamic collapse. It is not known whether some biologic agents for melanoma treatment may increase the propensity for cardiac metastasis, or whether this is simply the consequence of improved survival and the natural history of this tumor of presumed neuroendocrine origin. ${ }^{49}$

\section{Conflicts of Interest}

None.

\section{References}

1. Burke AP, Veinot JP, Loire R, et al. Tumours of the heart. In: Travis WD, Brambilla E, Müller-Hermelink HK, Harris CC (eds). Pathology and Genetics of Tumours of Lung, Pleura, Thymus and Heart. Lyon, France: IARC Press; 2004, pp. 250-88.

2. Paydarfar D, Krieger D, Dib N, et al. In vivo magnetic resonance imaging and surgical histopathology of intracardiac masses: distinct features of subacute thrombi. Cardiology. 2001;95:40-7.

3. Bussani R, De-Giorgio F, Abbate A, Silvestri F. Cardiac metastases. J Clin Pathol. 2007;60:27-34.

4. Al-Mamgani A, Baartman L, Baaijens M, de Pree I, Incrocci L, Levendag PC. Cardiac metastases. Int J Clin Oncol. 2008;13: 369-72.

5. Butany J, Leong SW, Carmichael K, Komeda M. A 30-year analysis of cardiac neoplasms at autopsy. Can J Cardiol. 2005;21:675-80.

6. Reynen K. Cardiac myxomas. N Engl J Med. 1995;333:1610-7.

7. Roberts WC. Primary and secondary neoplasms of the heart. Am J Cardiol. 1997;80:671-80.

8. Neragi-Miandoab S, Kim J, Vlahakes GJ. Malignant tumours of the heart: a review of tumour type, diagnosis and therapy. Clin Oncol ( $R$ Coll Radiol). 2007;19:748-56.

9. Butany J, Nair V, Naseemuddin A, Nair GM, Catton C, Yau T. Cardiac tumours: diagnosis and management. Lancet Oncol. 2005;6:219-28.

10. Ozyuncu N, Sahin M, Altin T, Karaoguz R, Guldal M, Akyurek O. Cardiac metastasis of malignant melanoma: a rare cause of complete atrioventricular block. Europace. 2006;8:545-8.

11. Miyake CY, Del Nido PJ, Alexander ME, et al. Cardiac tumors and associated arrhythmias in pediatric patients, with observations on surgical therapy for ventricular tachycardia. $\mathrm{J}$ Am Coll Cardiol. 2001;58:1903-9.

12. Garson A Jr, Smith RT Jr, Moak JP, et al. Incessant ventricular tachycardia in infants: myocardial hamartomas and surgical cure. J Am Coll Cardiol. 1987;10:619-26.

13. Myers KA, Wong KK, Tipple M, Sanatani S. Benign cardiac tumours, malignant arrhythmias. Can J Cardiol. 2010;26:e58-61.

14. Sheldon R, Isaac D. Metastatic melanoma to the heart presenting with ventricular tachycardia. Chest. 1991;99:1296-8.

15. Sharma J, Brunson JM, Memon N, Khakoo AY. Metastatic melanoma presenting as polymorphic ventricular tachycardia. Tex Heart Inst J. 2012;39:890-3.

16. Hanfling SM. Metastatic cancer to the heart. Review of the literature and report of 127 cases. Circulation. 1960;22:473-84.

17. Reynen K, Köckeritz U, Strasser RH. Metastases to the heart. Ann Oncol. 2004;15:375-81. 
18. Davies MJ. Tumours of the heart and pericardium. In: Pommerance A, Davies MJ (eds). The Pathology of the Heart. Oxford: Blackwell Scientific Publications; 1975, pp. 413-39.

19. Chin AJ, Saint-Jeannet JP, Lo CW. How insights from cardiovascular developmental biology have impacted the care of infants and children with congenital cardiac disease. Mech Dev. 2012;129:75-97.

20. Stoller JZ, Epstein JA. Cardiac neural crest. Semin Cell Dev Biol. 2005;16:704-15.

21. Brugada J, Brugada R, Brugada P. Channelopathies: a new category of diseases causing sudden death. Herz. 2007;32:185-91.

22. Choudhuri I, Pinninti M, Marwali MR, Sra J, Akhtar M. Polymorphic ventricular tachycardia-part I: structural heart disease and acquired causes. Curr Probl Cardiol. 2013;38:463-96.

23. Myerburg RJ. Epidemiology of ventricular tachycardia/ventricular fibrillation and sudden cardiac death. Pacing Clin Electrophysiol. 1986;9:1334-8.

24. Josephson ME, Horowitz LN, Farshidi A, Spielman SR, Michelson EL, Greenspan AM. Recurrent sustained ventricular tachycardia. 4. Pleomorphism. Circulation. 1979;59:459-68.

25. Stevenson WG, Weiss J, Wiener I, Wohlgelernter D, Yeatman L. Localization of slow conduction in a ventricular tachycardia circuit: implications for catheter ablation. Am Heart J. 1987;114:1253-8.

26. Costeas C, Peters NS, Waldecker B, Ciaccio EJ, Wit AL, Coromilas J. Mechanisms causing sustained ventricular tachycardia with multiple QRS morphologies: results of mapping studies in the infarcted canine heart. Circulation. 1997;96:3721-31.

27. Waspe LE, Brodman R, Kim SG, et al. Activation mapping in patients with coronary artery disease with multiple ventricular tachycardia configurations: occurrence and therapeutic implications of widely separate sites of origin. J Am Coll Cardiol. 1985;5:1075-86.

28. Richards DA, Blake GJ, Spear JF, Moore EN. Electrophysiologic substrate for ventricular tachycardia: correlation of properties in vivo and in vitro. Circulation. 1984;69:369-81.

29. Stevenson WG, Khan H, Sager P, et al. Identification of reentry circuit sites during catheter mapping and radiofrequency ablation of ventricular tachycardia late after myocardial infarction. Circulation. 1993;88:1647-70.

30. Stevenson WG, Nademanee K, Weiss JN, et al. Programmed electrical stimulation at potential ventricular reentry circuit sites. Comparison of observations in humans with predictions from computer simulations. Circulation. 1989;80:793-806.

31. Gray RA, Jalife J, Panfilov A, et al. Nonstationary vortexlike reentrant activity as a mechanism of polymorphic ventricular tachycardia in the isolated rabbit heart. Circulation. 1995;91:2454-69.

32. Pertsov AM, Davidenko JM, Salomonsz R, Baxter WT, Jalife J. Spiral waves of excitation underlie reentrant activity in isolated cardiac muscle. Circ Res. 1993;72:631-50.

33. Zipes DP, Camm AJ, Borggrefe M. ACC/AHA/ESC 2006 guidelines for management of patients with ventricular arrhythmias and the prevention of sudden cardiac death--executive summary. J Am Coll Cardiol. 2006;48:1064-108.
34. Debourdeau P, Gligorov J, Teixeira L, Aletti M, Zammit C. Malignant cardiac tumors. Bull Cancer. 2004;91 Suppl 3:136-46.

35. Parissis H, Al-Alao BS, Young VK. Case report and literature review: surgical treatment of a right atrial metastatic melanoma from a previously resected "advanced" primary site with regional lymph nodes involvement. Gen Thorac Cardiovasc Surg. 2012;60:655-60.

36. Chen RH, Gaos CM, Frazier OH. Complete resection of a right atrial intracavitary metastatic melanoma. Ann Thorac Surg. 1996;61:1255-7.

37. Onan B, Onan IS, Polat B. Surgical resection of solitary metastasis of malignant melanoma to the right atrium. Tex Heart Inst $J$. 2010;37:598-601.

38. Gabelman C, Al-Sadir J, Lamberti J, et al. Surgical treatment of recurrent primary malignant tumor of the left atrium. $J$ Thorac Cardiovasc Surg. 1979;77:914-21.

39. Reardon MJ, Walkes JC, Benjamin R. Therapy insight: malignant primary cardiac tumors. Nat Clin Pract Cardiovasc Med. 2006;3:548-53.

40. Blackmon SH, Patel AR, Bruckner BA, et al. Cardiac autotransplantation for malignant or complex primary left-heart tumors. Tex Heart Inst J. 2008;35:296-300.

41. Lui P, Cashin R, Machado M, Hemels M, Corey-Lisle PK, Einarson TR. Treatments for metastatic melanoma: synthesis of evidence from randomized trials. Cancer Treat Rev. 2007;33:665-80.

42. Middleton MR, Grob JJ, Aaronson N, et al. Randomized phase III study of temozolomide versus dacarbazine in the treatment of patients with advanced metastatic malignant melanoma. J Clin Oncol. 2000;18:158-66.

43. Hodi FS, O'Day SJ, McDermott DF, et al. Improved survival with ipilimumab in patients with metastatic melanoma. $N$ Engl $\mathrm{J} \mathrm{Med.}$ 2010;363:711-23.

44. Chapman PB, Hauschild A, Robert C, et al. Improved survival with vemurafenib in melanoma with BRAF V600E mutation. $N$ Engl $J$ Med. 2011;364:2507-16.

45. Bhatia S, Tykodi SS, Thompson JA. Treatment of metastatic melanoma: an overview. Oncology (Williston Park). 2009;23:488-96.

46. Simpson L, Kumar SK, Okuno SH. Malignant primary cardiac tumors: review of a single institution experience. Cancer. 2008;112:2440-6.

47. Hiniker SM, Chen DS, Reddy S. A systemic complete response of metastatic melanoma to local radiation and immunotherapy. Transl Oncol. 2012;5:404-7.

48. Seung SK, Curti BD, Crittenden M, et al. Phase 1 study of stereotactic body radiotherapy and interleukin-2--tumor and immunological responses. Sci Transl Med. 2012;4:137ra74.

49. Aronson D, Burger AJ. Neurohumoral activation and ventricular arrhythmias in patients with decompensated congestive heart failure: role of endothelin. Pacing Clin Electrophysiol. 2003;26:703-10.

(C) 2014 Aurora Health Care, Inc. 